\title{
OPTIMALISASI PELAYANAN DENGAN METODE ANTRIAN PADA SPBU ABC
}

\author{
Alloysius Vendhi Prasmoro' ${ }^{1)}$, Murwan Widyantoro ${ }^{2)}$, Warniningsih ${ }^{3}$ ) \\ 1) 2) Universitas Bhayangkara Jakarta Raya ${ }^{3)}$ Fakultas Teknologi Sumber Daya Alam, Institut Teknologi \\ Yogyakarta \\ email: alloysius.vendhi@dsn.ubharajaya.ac.id ${ }^{1)}, \underline{\text { murwan@dsn.ubharaja.ac.id }}^{2)}$
}

\begin{abstract}
ABSTRAK
Penelitian ini bertujuan untuk menganalisis jumlah jalur fasilitas yang optimal dan kinerja waktu pelayanan yang optimal pada jalur antrian sepeda motor yang ada pada SPBU ABC. Metode analisis yang digunakan adalah analisis teori antrian dan dianalisis sebagai model multi channel-single phase. hasil dari penelitian pada SPBU ABC dengan menggunakan analisis teori antrian yaitu dengan perhitungan model multi channel-single phase. menunjukkan bahwa setelah dianalisis dengan penambahan jalur pelayanan dan juga operator bisa lebih optimal dan dari segi waktu pelayanan dari yang awalnya satu jalur pelayanan menjadi dua jalur pelayanan dan rata-rata intensitas pelayanan yang awalnya 98\% menjadi $34 \%$ untuk rata-rata pelanggan dalam antrian 46 orang menjadi 1 orang dan untuk rata-rata pelanggan dalam sistem 47 orang menjadi 2 orang dan untuk rata-rata waktu menunggu dalam antrian dari 58,7 menit menjadi 0,38 menit kemudian untuk rata-rata menunggu dalam sistem 60 menit menjadi 1,6 menit. Untuk itu dengan sistem multi channel single-phase atau penambahan menjadi dua jalur dari segi waktu menjadi lebih optimal.
\end{abstract}

Kata kunci: Teori Antrian, Multi Channel-Single Phase, jalur pelayanan, waktu menunggu, rata-rata pelanggan

\section{OPTIMIZATION OF SERVICES WITH THE QUEUE METHOD AT ABC Gas Station}

\begin{abstract}
This study aims to analyze the optimal number of facility paths and the optimal service performance time on the motorcycle queue line available at the $A B C$ gas station. The analytical method used is the analysis of queuing theory and analyzed as multi-channel single phase model. the results of the research at the ABC gas station using queuing theory analysis is the calculation of multi-channel single-phase models. shows that after analyzing with the addition of service line and also operator can be more optimal and in terms of service time from initially one service line into two service line and average service intensity which initially $98 \%$ to $34 \%$ for average customer in queue 46 person to 1 person and for the average customer in the system 47 people to 2 people and for the average waiting time in the queue from 58.7 minutes to 0.38 minutes later for the average wait in the system 60 minutes to 1.6 minute. For that, with single-phase multi-channel or addition to two lines in terms of time, it becomes more optimal.
\end{abstract}

Keywords: Queue Theory, Multi Channel- Single Phase, service route, waiting time, customer average

\section{PENDAHULUAN}

Dalam dunia usaha, bertambahnya konsumen berarti bertambah pula transaksi usaha yang menyebabkan jumlah antrian yang memanjang. Umumnya, tiap orang pernah mengalami peristiwa ini dalam hidupnya, karena antrian sudah menjadi bagian dari kehidupan setiap orang. Meskipun antrian sudah menjadi hal yang biasa, dalam kondisi tertentu pelanggan harus menunggu dalam waktu yang bervariasi, ada yang sebentar, ada yang lama, bahkan ada yang sangat lama, sehingga menimbulkan keresahan. Para manager dituntut untuk berpikir bagaimana cara agar konsumen tidak perlu menunggu lama, sehingga pemahaman mengenai teori antrian pun sangat dibutuhkan dalam mengambil keputusan mengenai model antrian yang paling tepat untuk menunjang kelancaran operasi perusahaan. Dewasa ini, jumlah produksi kendaraan bermotor semakin meningkat, disebabkan oleh tingginya jumlah permintaan pelanggan setiap tahun. Tercatat peningkatan sepeda motor di Jawa Barat, sebanyak 13,725,590 juta unit. Sementara di kabupaten Bekasi sendiri di angka 1,231,699 juta (BPS, 2016). Dengan bertambahnya jumlah sepada motor di setiap tahunnya, maka jumlah antrian di Stasiun Pengisian Bahan Bakar Umum akan memanjang. Sebagai contoh SPBU ABC yang setiap harinya selalu terjadi antrian panjang di jam-jam sibuk. SPBU ABC ini menjadi satu-satunya SPBU yang cukup sering didatangi pelanggan atau masyarakat, karena terletak di jalur yang strategis atau sering dilewati masyarakat Bekasi yang bekerja ke Jakarta dan bagi masyarakat setempat yang ingin beraktivitas setiap harinya. 
Pelayanan yang baik sangat penting diterapkan oleh perusahaan untuk selalu mengambil hati konsumen, karena pelayanan yang baik diharapkan memenuhi kebutuhan dan keinginan pelanggan. Pemandangan mengantri di Indonesia sangat sering kita lihat. Antrian terjadi karena keterbatasan kapasitas pelayanan. Antrian yang terlalu panjang dapat merugikan pelanggan maupun penyedia layanan jasa. Hal ini terjadi apabila terdapat pelanggan yang tidak sabar mengantri karena menunggu terlalu lama sehingga memutuskan untuk meninggalkan antrian (Febriani dan Sahid, 2018). SPBU $\mathrm{ABC}$ ini menyediakan satu jalur fasilitas pengisian bahan bakar untuk pengendara motor, dengan jenis bahan bakar Pertamax, Pertalite dan Premium. Pada satu jalur fasilitas ini terdapat satu operator, diharapkan dapat mengurangi masalah antrian ketika pelanggan datang pada saat tertentu untuk memenuhi kebutuhannya. Penulis menganalisis hanya pada jalur antrian sepeda motor di SPBU ABC menggunakan model antrian single channel single phase dengan disiplin antrian first in first out dimana pelanggan yang datang lebih awal akan dilayani terlebih dahulu oleh operator SPBU, untuk menganalisis dibutuhkan data awal kedatangan pelanggan pada pengisian bahan bakar sepeda motor. Berikut di bawah ini data kedatangan pelanggan selama 4 minggu dalam 8 jam kerja di SPBU ABC pada tabel 1.1.

Tabel. 1.1 Data kedatangan pelanggan SPBU ABC

No Hari Tanggal Kedatangan Total Jam

\begin{tabular}{llll}
\cline { 3 - 3 } & & $\begin{array}{l}\text { Pelanggan } \\
\text { (Unit) }\end{array}$ & Kerja \\
\hline $\mathbf{1}$ & Senin & $25 / 03 / 2019$ & 392 \\
\hline $\mathbf{2}$ & Selasa & $26 / 03 / 2019$ & 374 \\
\hline $\mathbf{3}$ & Rabu & $27 / 03 / 2019$ & 357 \\
\hline $\mathbf{4}$ & Kamis & $28 / 03 / 2019$ & 341 \\
\hline $\mathbf{5}$ & Jumat & $29 / 03 / 2019$ & 322 \\
\hline $\mathbf{6}$ & Sabtu & $30 / 03 / 2019$ & 388 \\
\hline $\mathbf{7}$ & Minggu & $31 / 03 / 2019$ & 331 \\
\hline $\mathbf{8}$ & Senin & $01 / 04 / 2019$ & 412 \\
\hline $\mathbf{9}$ & Selasa & $02 / 04 / 2019$ & 377 \\
\hline $\mathbf{1 0}$ & Rabu & $03 / 04 / 2019$ & 362 \\
\hline $\mathbf{1 1}$ & Kamis & $04 / 04 / 2019$ & 379 \\
\hline $\mathbf{1 2}$ & Jumat & $05 / 04 / 2019$ & 338 \\
\hline $\mathbf{1 3}$ & Sabtu & $06 / 04 / 2019$ & 383 \\
\hline $\mathbf{1 4}$ & Minggu & $07 / 04 / 2019$ & 364 \\
\hline $\mathbf{1 5}$ & Senin & $08 / 04 / 2019$ & 420 \\
\hline $\mathbf{1 6}$ & Selasa & $09 / 04 / 2019$ & 380 \\
\hline $\mathbf{1 7}$ & Rabu & $10 / 04 / 2019$ & 382 \\
\hline $\mathbf{1 8}$ & Kamis & $11 / 04 / 2019$ & 385 \\
\hline $\mathbf{1 9}$ & Jumat & $12 / 04 / 2019$ & 346 \\
\hline $\mathbf{2 0}$ & Sabtu & $13 / 04 / 2019$ & 399 \\
\hline $\mathbf{2 1}$ & Minggu & $14 / 04 / 2019$ & 368 \\
\hline $\mathbf{2 2}$ & Senin & $15 / 04 / 2019$ & 396 \\
\hline $\mathbf{2 3}$ & Selasa & $16 / 04 / 2019$ & 379 \\
\hline $\mathbf{2 4}$ & Rabu & $17 / 04 / 2019$ & 366 \\
\hline $\mathbf{2 5}$ & Kamis & $18 / 04 / 2019$ & 398 \\
\hline $\mathbf{2 6}$ & Jumat & $19 / 04 / 2019$ & 359 \\
\hline $\mathbf{2 7}$ & Sabtu & $20 / 04 / 2019$ & 409 \\
\hline $\mathbf{2 8}$ & Minggu & $21 / 04 / 2019$ & 345 \\
\hline Total & & & 10452 \\
$\mathbf{D a t a}$ & $(2019)$ & & \\
\hline
\end{tabular}

Sumber : Pengolahan Data (2019) 
Berdasarkan data yang ada pada tabel 1.1 diatas merupakan data kedatangan pelanggan selama 4 minggu dari tanggal 25 Maret 2019 sampai dengan 21 April 2019 dengan total keseluruhan 10,452 orang dan untuk melihat permasalahan antrian yang ada seperti panjang antrian pelanggan, jumlah pelanggan keluar antrian dari 7 hari dan berikut di bawah ini tabel 1.2.

\begin{tabular}{|c|c|c|c|c|}
\hline Hari & \begin{tabular}{l}
\multicolumn{1}{c}{ Rata- } \\
Rata \\
Panjang
\end{tabular} & $\begin{array}{l}\text { Rata-Rata } \\
\text { Jumlah } \\
\text { Pelanggan }\end{array}$ & $\begin{array}{l}\text { Rata- } \\
\text { Rata } \\
\text { Waktu }\end{array}$ & $\begin{array}{l}\text { Rata- } \\
\text { Rata } \\
\text { Waktu }\end{array}$ \\
\hline & $\begin{array}{c}\text { Antrian } \\
\text { Pelanggan }\end{array}$ & $\begin{array}{l}\text { Keluar } \\
\text { Antrian }\end{array}$ & $\begin{array}{l}\text { Menunggu } \\
\text { (Menit) }\end{array}$ & $\begin{array}{l}\text { Pelayanan } \\
\text { Per Orang } \\
\text { (Menit) }\end{array}$ \\
\hline Senin & 50 & 13 & 58,8 & 1,18 \\
\hline Selasa & 42 & 7 & 53,3 & 1,26 \\
\hline Rabu & 41 & 7 & 53,2 & 1,29 \\
\hline Kamis & 46 & 9 & 58.75 & 1,27 \\
\hline Jumat & 46 & 7 & 65,2 & 1,41 \\
\hline Sabtu & 54 & 10 & 65,48 & 1,21 \\
\hline Minggu & 54 & 8 & 73,6 & 1,36 \\
\hline Total & 333 & 61 & 369,58 & 8,98 \\
\hline $\begin{array}{l}\text { Rata- } \\
\text { Rata }\end{array}$ & 47,5 & 8,7 & 52,6 & 1,28 \\
\hline
\end{tabular}

Kesimpulan dapat ditarik dari Tabel 1.2. di atas dari total satu minggu kerja dengan rata-rata panjang antrian pelanggan total selama satu minggu yang sudah dirata-rata dari total empat minggu adalah 333 dengan rata-rata panjang antrian 47,5 dan rata-rata jumlah pelanggan keluar antrian dengan total selama satu minggu yang sudah dirata-rata dari total empat minggu adalah 61 dengan rata-rata pelanggan keluar antrian sebanyak 8,7 dan rata-rata waktu menunggu dengan total selama satu minggu yang sudah dirata-rata dari total empat minggu adalah 369,58 dengan rata-rata waktu menunggu 52,6 menit dan untuk rata-rata waktu pelayanan per orang dengan total selama satu minggu yang sudah dirata-rata 8,98 menit dan untuk rata-rata waktu pelayanan per orang sebanyak 1,28 menit.

\section{LANDASAN TEORI}

Menurut Lusiani dan Irawan (2016), antrian adalah suatu kejadian yang biasa dalam kehidupan sehari-hari. Antrian yang panjang sering kali kita lihat di bank saat nasabah mengantri di teller untuk melakukan transaksi mobil antri untuk mencuci dan masih banyak contoh lainnya. Di sektor jasa bagi sebagian orang, antri merupakan hal yang membosankan, oleh sebab itu terlalu lama mengantri akan menyebabkan pelanggan pergi. Hal ini merupakan kerugian bagi perusahaan tersebut. Antrian timbul dikarenakan oleh kebutuhan akan layanan melebihi kapasitas (kemampuan) pelayanan atau fasilitas layanan, sehingga pengguna fasilitas yang tiba tidak bisa segera mendapat layanan disebabkan kesibukan layanan, didalam suatu antrian yang optimal tidak hanya berdasarkan pada waktu menunggu yang lama maupun waktu menunggu yang cepat tetapi mendapatkan standar dari setiap waktu menunggu dan pelayanan dalam antrian tersebut. Maister, (1986 dan Jones dan Peppiatt, 1996 dalam Lusiani, 2016) menemukan bahwa seseorang yang menunggu dalam antrian akan merasakan waktu lebih lama dibandingkan menunggu di dalam grup.

\section{Faktor Sistem Antrian}

Menurut Kakiay (2004) dalam Arum et al., (2014), faktor-faktor yang berpengaruh terhadap barisan antrian dan pelayanannya adalah sebagai berikut :

(1) Distribusi Kedatangan

Pola kedatangan para pelanggan biasanya dicirikan oleh waktu antar-kedatangan, yaitu waktu antara kedatangan dua pelanggan yang berurutan pada suatu fasilitas pelayanan. Pola ini dapat bergantung pada jumlah pelanggan yang berada dalam sistem, ataupun tidak bergantung pada keadaan sistem antrian ini.

(2) Distribusi Waktu

Pelayanan Pola pelayanan biasanya dicirikan oleh waktu pelayanan (service time), yaitu waktu yang dibutuhkan seorang pelayan untuk melayani seorang pelanggan. Waktu pelayanan dapat bersifat deterministik, atau berupa suatu variabel acak yang distribusi probabilitasnya dianggap telah diketahui. 
(3) Fasilitas Pelayanan

Bentuk seri, dalam satu garis lurus maupun garis melingkar.

b. Bentuk paralel, dalam beberapa garis lurus antara yang seri dengan yang paralel.

c. Bentuk rangkaian stasiun, yang dapat didesain secara seri dengan pelayanan lebih darisatu pada setiap stasiun. Bentuk ini dapat juga dilakukan secara paralel dengan stasiun yang berbeda-beda.

(4) Ukuran dalam Antrian

a. Ukuran kedatangan secara tidak terbatas (infinite queиe)

b. Ukuran kedatangan secara terbatas (finite quеие)

(5) Sumber Pemanggilan

a. Sumber pemanggilan tidak terbatas (infinite quеие)

b. Sumber pemanggilan secara terbatas (finite quеие)

Pada model single channel - single phase atau model antrian satu jalur dan satu tahapan, rumus-rumus yang digunakan adalah sebagai berikut :

(1) Probabilitas kesibukan fasilitas dalam sistem digunakan rumus $(\mathrm{Pw})$ :

$\mathrm{Pw}=\frac{\lambda}{\mu}$

(2) Panjang rata-rata pengunjung dalam antrian (Lq) :

$L q=\frac{\lambda^{2}}{\mu(\mu-\lambda)}$

(3) Panjang rata-rata pengunjung dalam sistem (Ls) :

$L s=\frac{\lambda}{\mu-\lambda}$

(4) Waktu rata-rata dalam antrian (Wq) :

$W q=\frac{\lambda}{\mu(\mu-\lambda)}$

(5) Waktu rata-rata dalam sistem (Ws) :

$W s=\frac{1}{\mu-\lambda}$

Untuk fasilitas sistem antrian Multi Channel - Single Phase atau model antrian dengan beberapa jalur dengan satu tahapan, rumus yang digunakan sebagai berikut :

(1) Probabilitas terdapat 0 orang dalam sistem (Po)

$P o=\frac{1}{\left[\sum_{n=0}^{M-1} \frac{1}{n !}\left(\frac{\lambda}{\mu}\right) n\right]+\frac{1}{M !}\left(\frac{\lambda}{\mu}\right) \mathrm{M} \frac{M \mu}{M \mu-\Omega}}$

(2) Jumlah pelanggan rata-rata dalam sistem (Ls) :

$\mathrm{Ls}=\frac{\lambda \mu(\lambda / \mu) M}{(\mathrm{M}-1)\left(\mathrm{M}_{\mu}-\lambda\right)^{2}} P 0+\frac{\lambda}{\mu}$

(3) Waktu rata-rata yang dihabiskan seorang pelanggan dalam antrian atau sedang dilayani (dalam sistem)

$\mathrm{Ws}=\frac{L S}{\lambda}$

(4) Jumlah orang/unit rata-rata yang menunggu dalam antrian (Lq) :

$L q=L s-\frac{\lambda}{\mu}$

(5) Waktu rata-rata yang dihabiskan oleh seorang pelanggan dalam menunggu didalam antrian (Wq): $W q=\frac{L q}{\lambda}$ 
Perhitungan untuk biaya yang dikeluarkan, baik berupa biaya yang dikeluarkan oleh pelanggan saat menunggu dan biaya yang digunakan untuk fasilitas antrian menggunakan rumus sebagai berikut :

Biaya fasilitas

$\mathrm{E}(\mathrm{Cs})=\mathrm{S} . \mathrm{Cs}$

E (Cs) menunjukan jumlah biaya yang dikeluarkan untuk fasilitas per satuan waktu, S adalah jumlah jalur pelayanan yang disediakan, dan Cs adalah biaya yang dikeluarkan untuk fasilitas per satuan waktu.

\section{Uji Kecukupan Data}

Dalam proses pengukuran waktu kerja, diperlukan kegiatan pengujian terhadap data yang dikumpulkan. Kegiatan pengujian tersebut dimulai dari analisa atas konsistensi kerja operator. Pengujian data yang pertama adalah uji kecukupan data. Uji kecukupan data diperlukan untuk memastikan bahwa data yang telah dikumpulkan adalah cukup secara objektif. Test kecukpan data dapat dilakukan dengan menggunakan rumus sebagai berikut.

$$
\mathrm{N}^{\prime}=\left[\frac{k}{s} \frac{\sqrt{\sum X^{2}-\left(\sum X\right)^{2}}}{\sum X}\right]^{2}
$$

\section{METODE PENELITIAN}

Dalam melakukan pengumpulan data untuk dianalisis, penulis melakukan beberapa cara. Di antaranya :

\section{Observasi lapangan}

Metode observasi yaitu pengumpulan data dengan mengamati secara langsung terhadap objek penelitian yang bersangkutan. Hasil observasi dapat dijadikan sebagai data pendukung untuk menganalisis dan mengambil keputusan. .

2. Wawancara

Metode wawancara bertujuan untuk mengetahui sistem dengan mengadakan tanya jawab kepada penanggung jawab SPBU ABC.

\section{Studi pustaka}

Teknik ini merupakan cara yang dilakukan untuk mendapatkan informasi dari berbagai sumber yang dapat membantu tercapainya penelitian yang baik. Seperti buku referensi, jurnal, dan data internal perusahaan.

\section{Instrumen Penelitian}

Instrumen-instrumen yang digunakan dalam penelitian ini adalah:

1. Worksheet untuk mencatat data-data primer yang diperoleh seperti data jumlah dan waktu kedatangan pelanggan.

2. CCTV untuk perhitungan jumlah kedatangan pelanggan yang tertinggal.

\section{Teknik Pengolahan Data}

3. Alat tulis untuk mencatat data-data primer secara manual.

Setelah melakukan teknik pengumpulan data untuk penelitian, maka tahapan selanjutnya adalah melakukan pengolahan data. di antaranya :

1. Pada tahap awal dilakukan uji kecukupan data

2. Menentukan Model Sistem Antrian

3. Menghitung tingkat kedatangan dan tingkat pelayanan

4. Menentukan penyebab masalah antrian

5. Memberikan solusi

\section{ANALISIS DATA DAN PEMBAHASAN \\ Uji Kecukupan Data}

Sebelum data yang diperoleh diolah lebih lanjut, dilakukan terlebih dahulu pengujian kecukupan data untuk mengetahui data yang didapatkan sudah cukup atau masih kurang. Dalam perhitungan uji kecukupan data juga diperlukan tingkat ketelitian dan tingkat keyakinan. Di dalam aktivitas pengukuran kerja akan diambil tingkat ketelitian 5\% dan tingkat keyakinan 95\%. Uji kecukupan data dengan tingkat kepercayaan $95 \%(\mathrm{k}=2)$ dan tingkat ketelitian $5 \%(0,05)$ menunjukkan sekurang-kurangnya 95 dari 100 harga rata-rata dari data yang diukur memiliki penyimpangan tidak melebihi 5\%. Perhitungan uji kecukupan data didapat dengan menggunakan persamaan 2.12 


$$
\begin{aligned}
& \mathrm{N}^{\prime}=\left[\frac{k}{s} \frac{\sqrt{\sum X^{2}-\left(\sum X\right)^{2}}}{\Sigma X}\right]^{2} \\
& \mathrm{~N}^{\prime}=\left[\frac{2}{0,05} \frac{\sqrt{30 x 3918340-(109244304)}}{10452}\right] \mathrm{N}^{\prime}=11,029
\end{aligned}
$$

Data $\mathrm{N}^{\prime}(11,029) \leq \mathrm{N}(30)$, maka data dinyatakan cukup.

Tabel 2. Hasil Perhitungan Single Channel-Single Phase

\begin{tabular}{lllllll}
\hline No. Hari & \multicolumn{3}{c}{ Aspek perhitungan } \\
\cline { 3 - 6 } & & Pw & Lq & Ls & Wq & Ws \\
\cline { 3 - 7 } & & & (Orang) & (Orang) & (Menit) & (Menit) \\
\hline $\mathbf{1}$ & Senin & $98 \%$ & 50 & 51 & 58,8 & 60 \\
\hline $\mathbf{2}$ & Selasa & $98 \%$ & 42 & 43 & 53,3 & 54 \\
\hline $\mathbf{3}$ & Rabu & $98 \%$ & 41 & 42 & 53,2 & 54 \\
\hline $\mathbf{4}$ & Kamis & $98 \%$ & 46 & 47 & 58,75 & 60 \\
\hline $\mathbf{5}$ & Jumat & $98 \%$ & 46 & 47 & 65,2 & 66 \\
\hline $\mathbf{6}$ & Sabtu & $98 \%$ & 54 & 55 & 65,48 & 66 \\
\hline $\mathbf{7}$ & Minggu & $98 \%$ & 54 & 55 & 73,6 & 75 \\
\hline $\mathbf{8}$ & Rata- & $98 \%$ & 46 & 47 & 58,7 & 60 \\
\hline & Rata & & & & & \\
\hline
\end{tabular}

(Sumber : Pengolahan Data 2019)

Berdasarkan aspek perhitungan yang ada pada tabel 4.2. di atas persentase antrian dari hari senin sampai dengan hari minggu yaitu $98 \%$. Kemudian jumlah rata-rata dalam antrian (Lq) senin sebanyak 50 orang, selasa sebanyak 42 orang, rabu sebanyak 41 orang, kamis sebanyak 46 orang, jumat sebanyak 46 orang, sabtu sebanyak 54 orang, dan minggu 54 orang. Kemudian jumlah rata-rata dalam sistem (Ls) senin sebanyak 51 orang, selasa sebanyak 43 orang, rabu sebanyak 42 orang, kamis sebanyak 47 orang, jumat sebanyak 47 orang, sabtu sebanyak 55 orang, dan minggu 55 orang. Kemudian untuk rata-rata waktu menunggu antrian pada hari senin selama 58,8 menit, selasa selama 53,3 menit, rabu selama 53,2 menit, kamis selama 58,75 menit, jumat selama 65,2 menit, sabtu selama 65,48 menit, dan minggu selama 73,6 menit..berikut di bawah ini grafik untuk melihat persentase agar lebih mudah dilihat berikut gambar 4.2. grafik perhitungan dari perhitungan single channel-single phase. 


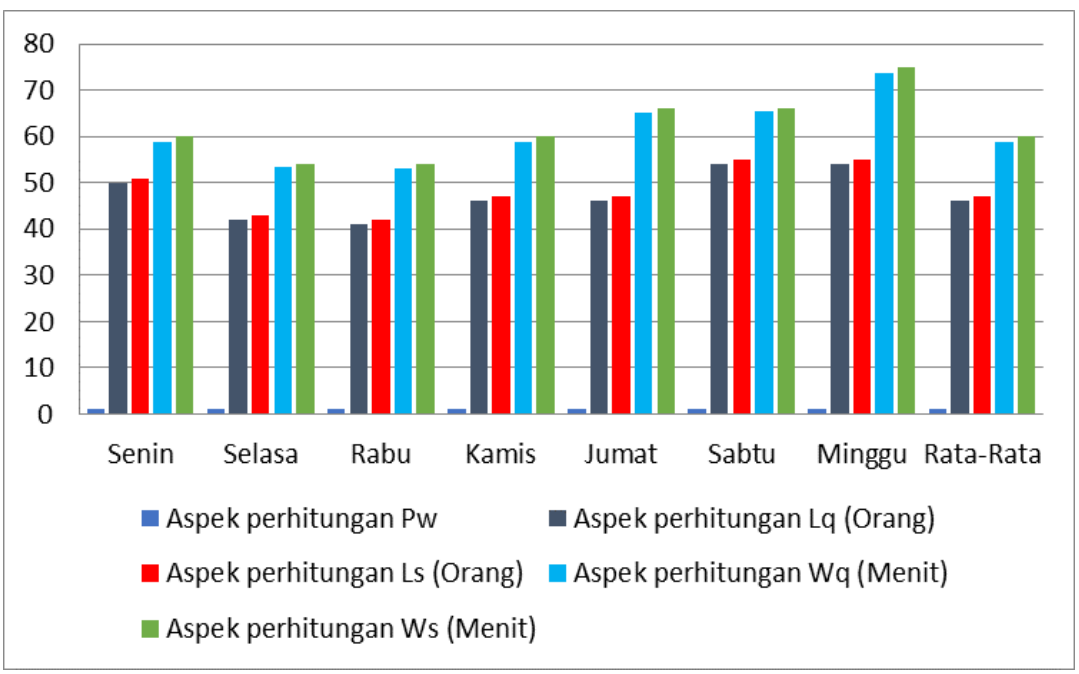

\section{Solusi Untuk Mengatasi Jumlah Pelayanan Antrian}

\section{Gambar 4.2. Grafik hasil perhitungan}

Dalam mengatasi panjang antrian menurut penulis solusi nya adalah dengan penambahan jalur pelayanan tetap memperhatikan berbagai aspek seperti biaya, perlengkapan, dan jumlah karyawan.

Untuk perhitungan ini, diasumsikan adannya penambahan satu operator dengan jumlah tahapan tetap sehingga jumlah pelayanan menjadi dua jalur pelayanan dengan hanya satu tahapan.Atau model antrian yang digunakan adalah Multi Channel Single Phase (M/M/2).

Untuk penambahan dilakukan dua jalur pelayanan dikarenakan pada saat antrian yang panjang sedangkan operator yang ada hanya satu dan berakibat antrian yang panjang. Dengan menggunakan data $(\boldsymbol{\lambda})$ dan $(\boldsymbol{\mu})$ yang sama yang ada pada tabel 4.1. analisis perhitungan untuk sistem antrian menggunakan dua jalur dapat dilihat pada perhitungan berikut ini.

Senin $\lambda=50,6 \mu=51,6 \mathrm{M}=2$

Dengan menggunakan persamaan probabilitas tidak adannya pelanggan dalam fasilitas (Po) dapat dihitung sebagai berikut :

$$
\begin{aligned}
\frac{1}{\left[\sum_{n=0}^{M-1} \frac{1}{n !}\left(\frac{\lambda}{\mu}\right)^{n}\right]+\frac{1}{M_{!}}\left(\frac{\lambda}{\mu}\right)^{M} \frac{M \mu}{M_{\mu}-\lambda}} \\
=\frac{1}{(1+0,98)+\frac{1}{2}(0,98)^{2} \frac{103,2}{103,2-50,6}} \\
=\frac{1}{1,98+0,48 \times 1,96} \\
=0,34 \\
=34 \%
\end{aligned}
$$

Berdasarkan angka di atas menunjukkan biaya fasilitas dalam keadaan menunggu (siaga) sebesar 0,34 atau persentasenya $34 \%$ dari waktu pelayanan. Jumlah rata - rata pelanggan dalam sistem (Ls) dapat dihitung menggunakan persamaan 2.7. dengan hasil sebagai berikut :

$$
\begin{aligned}
& =\frac{2.610,9 \cdot 0,96}{1(2,766,7)} 0,34+0,98 \\
= & 0,90 \times 0,34+0,98 \\
= & 1,28 \text { Orang }
\end{aligned}
$$

Berdasarkan angka di atas menunjukkan bahwa jumlah rata-rata pelanggan di dalam sistem adalah 1,28 orang atau dibulatkan menjadi 2 orang. Dengan menggunakan persamaan 2.10, jumlah waktu rata-rata pelanggan dalam antrian $(\mathrm{Wq})$ dan untuk perhitungannya sebagai berikut. 


$$
\mathrm{Wq}=\frac{0,3}{50,6}=0,35 \text { menit }
$$

Berdasarkan angka tersebut menunjukkan bahwa jumlah rata-rata pelanggan berada dalam antrian selama 0,35 Menit

Jumlah waktu rata-rata pelanggan dalam sistem (Ws) dapat dihitung dengan persamaan 2.8. dengan hasil sebagai berikut :

$$
\mathrm{Ws}=\frac{\mathrm{Ls}}{\lambda}=\frac{1,28}{46,7}=1,64 \text { Menit }
$$

Berdasarkan angka tersebut menunjukkan bahwa jumlah rata-rata pelanggan berada di dalam sistem selama 1,6 Menit

Dengan menggunakan persamaan 2.10, jumlah waktu rata-rata pelanggan dalam antrian (Wq) dan untuk perhitungannya sebagai berikut.

$\mathrm{Wq}=\frac{\mathrm{Lq}}{\lambda}=\frac{0,3}{46,7}=0,38$ Menit

Berdasarkan angka tersebut menunjukkan bahwa jumlah rata-rata pelanggan berada dalam antrian selama 0,38 Menit.

Tabel 3. Jumlah rata-rata pelanggan berada dalam antrian selama 0,38 Menit.

\begin{tabular}{lllllll}
\hline \multirow{2}{*}{ No. Hari } & \multicolumn{6}{l}{ Aspek perhitungan } \\
\cline { 3 - 7 } & & Pw & Lq & Ls & Wq & Ws \\
\cline { 3 - 7 } & & & (Orang) & (Orang) & (Menit) & (Menit) \\
\hline 1. & Senin & $34 \%$ & 1 & 2 & 0,35 & 1,5 \\
\hline 2. & Selasa & $34 \%$ & 1 & 2 & 0,38 & 1,6 \\
\hline 3. & Rabu & $34 \%$ & 1 & 2 & 0,38 & 1,2 \\
\hline 4. & Kamis & $34 \%$ & 1 & 2 & 0,37 & 1,6 \\
\hline 5. & Jumat & $34 \%$ & 1 & 2 & 0,28 & 1,6 \\
\hline 6. & Sabtu & $34 \%$ & 1 & 2 & 0,37 & 1,6 \\
\hline 7. & Minggu & $34 \%$ & 1 & 2 & 0,4 & 1,7 \\
\hline 8. & Rata- & $34 \%$ & 1 & 2 & 0,38 & 1,6 \\
& Rata & & & & & \\
\hline
\end{tabular}

Tabel 4. Perbandingan antara Single Channel Single-Phase dan Multi-Channel Single Phase Hari Aspek Perhitungan

$$
\text { Lq (Orang) Ls (Orang) Wq (Menit) Ws (Menit) }
$$

\begin{tabular}{lcccccccc}
\hline & $\mathrm{M}=1$ & $\mathrm{M}=2$ & $\mathrm{M}=1$ & $\mathrm{M}=2$ & $\mathrm{M}=1$ & $\mathrm{M}=2$ & $\mathrm{M}=1$ & $\mathrm{M}=2$ \\
\hline Senin & 50 & 1 & 51 & 2 & 58,8 & 0,35 & 60 & 1,5 \\
Selasa & 42 & 1 & 43 & 2 & 53,3 & 0,38 & 54 & 1,6 \\
Rabu & 41 & 1 & 42 & 2 & 53,2 & 0,38 & 54 & 1,2 \\
Kamis & 46 & 1 & 47 & 2 & 58,75 & 0,37 & 60 & 1,6
\end{tabular}




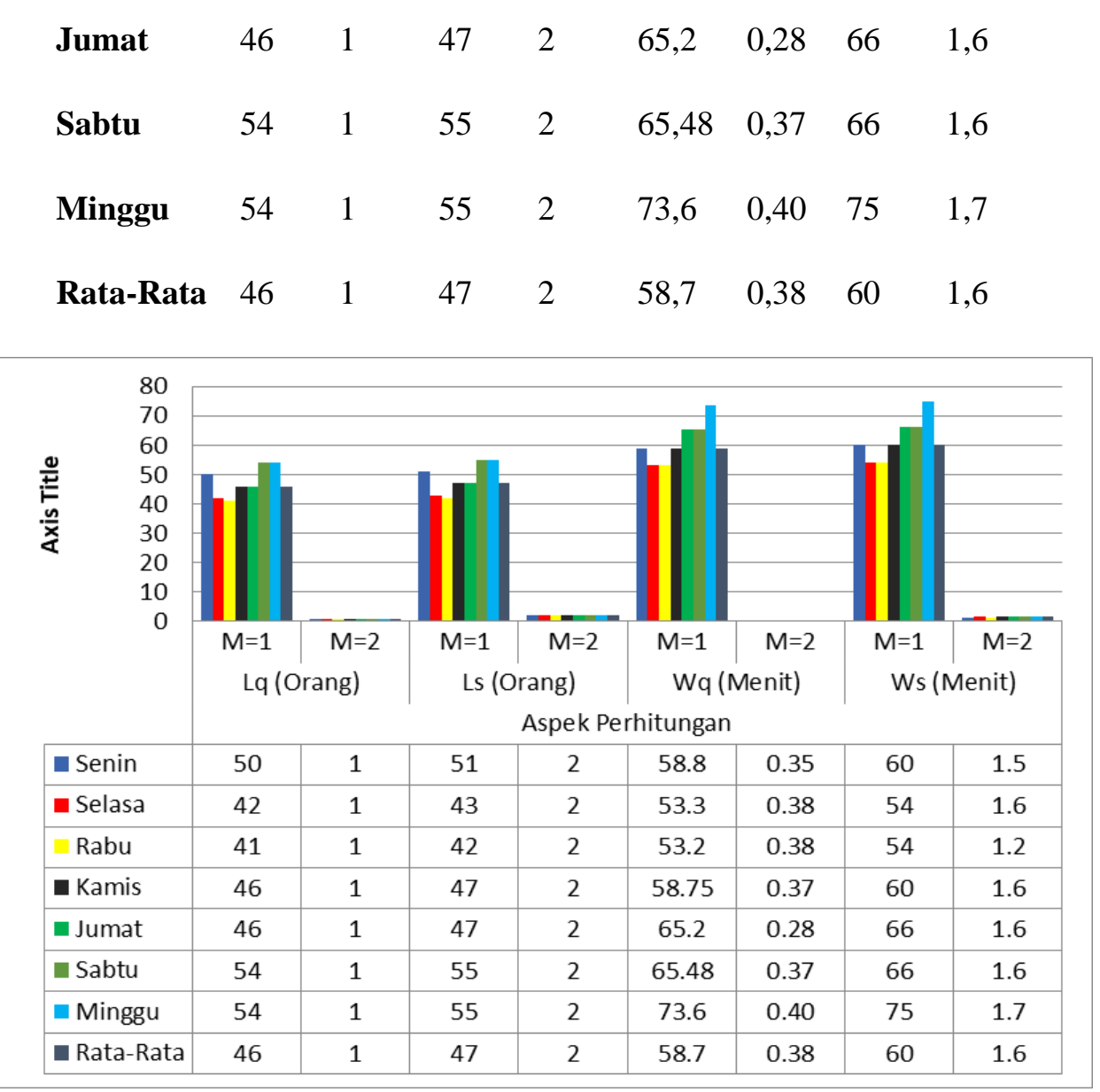

Berdasarkan tabel di atas menggambarkan terdapat perbedaan yang siginifikan antara satu jalur dan dua jalur dengan adannya jalur pelayanan yang ditambahkan, apabila hanya satu jalur maka terjadinnya antrian dan persentase kesibukannya di setiap harinnya $98 \%$ dan untuk dua jalur terjadinnya penurunan persentasennya menjadi $34 \%$ dan sebagai contoh di hari senin terdapat 50 orang yang menunggu dalam antrian, dan 51 orang yang menunggu di dalam sistem total, dan pelanggan akan menghabiskan 58,8 menit untuk menunggu dalam antrian dan 60 dalam sistem total. Dalam jumlah jalur pelayanan dua jalur, dan perbandingan antara rata-rata contoh di hari senin maka pelanggan yang mengantri dalam sistem 1 orang dan yang didalam sistem 2 orang.Selain itu, waktu yang dihabiskan pelanggan untuk mengantri menjadi 0,35 menit dan waktu dalam sistem 1,5 menit.

Dari tabel terlihat dengan bertambahnnya jalur pelayanan yang beroperasi, maka terjadinnya penurunan dalam antrian dan menjadi optimal dan bertambahnya jalur pelayanan yang beroperasi maka semakin banyak jumlah pelanggan yang mampu dilayani dalam pengisian bahan bakar di SPBU sehingga pelanggan akan lebih nyaman dari segi waktu pelayanan dan bisa bertambahnnya pelanggan yang datang.sehingga operator dalam melakukan pelayanan tidak tergesa-gesa karena banyaknya pelanggan dalam antrian. Dengan demikian, pelayanan yang diberikan oleh pihak SPBU akan semakin memuaskan pelanggan, dan dapat meningkatkan produktivitas dari kualitas SPBU. Berikut ini adalah flowchart aliran aktivitas pada sistem antrian di SPBU ABC setelah penerapan teori MultiChannel Single Phase dapat dilihat pada gambar 4.5 flowchart yang ada di bawah ini.

\section{KESIMPULAN DAN SARAN}

\section{Kesimpulan}

Berdasarkan hasil pengolahan data dan analisa yang telah dibahas pada bab sebelumnya dapat diambil kesimpulan sebagai berikut:

1. Dari perhitungan yang telah dilakukan, didapatkan jumlah jalur pelayanan yang optimalpada jalur sepeda motor adalah 2 jalur, dengan menambahkan 1 oprator.

2. Waktu pelayanan dan waktu tunggu yang opimal pada jalur sepeda motor di SPBU ABC adalah 0,38 menit untuk waktu pelayanan dan 1,6 menit untuk waktu tunggu.

3. Berdasarkan hasil perhitungan dengan model antrian satu jalur atau single channel-single phase $(\mathrm{M} / \mathrm{M} / 1)$ dan hasil perhitungan dengan model antrian dua jalur atau multi channel-single phase $(\mathrm{M} / \mathrm{M} / 2)$ dari sisi waktu pelayanan. Maka didapatkan perbandingan dari rata-rata selama setiap hari 
persentase antara single channel-single phase dan multi channel-single phase dari $98 \%$ terjadinya penurunan menjadi 34\% kemudian untuk rata-rata pelanggan dalam antrian dari 46 orang menjadi 1 orang dan untuk rata-rata pelanggan dalam sistem 47 orang menjadi 2 orang dan Untuk itu dengan multi channel single-phase atau penambahan menjadi dua jalur dari segi waktu menjadi lebih optimal.

\section{Saran}

1. Dalam melakukan pelayanan ke pelanggan, pihak SPBU disarankan membuka fasilitas jalur pelayanan lagi dengan penambahan satu operator lagi dan sehingga dengan adannya dua jalur yang melayani akan lebih cepat dan mengurangi antrian yang terjadi dan penambahan menjadi dua jalur yaitu dengan model multi channel-single phase $(\mathrm{M} / \mathrm{M} / 2)$.

2. Untuk penambahan jalur pelayanan ini dapat dilakukan dengan penambahan fasilitas dan perlengkapan untuk operator seperti seragam SPBU baju dan celana serta selang tambahan

\section{DAFTAR PUSTAKA}

Arum, P.R., Sugito. \& Wulandari, Y. (2014). Analisis Sistem Antrian Pelayanan Nasabah Bank X Kantor Wilayah Semarang. Journal GAUSSIAN, Vol 3, No 4.

Badan Pusat Statistika (BPS) Provinsi Jawa Barat. (2016, 1 Januari). Jumlah kendaraan bermotor menurut jenis tahun 2011-2015. Diakses tanggal 25 Maret 2019 dari http://www.bps.go.id/:

Febriani, D. \& Sahid. (2018). Analisis Antrian Sistem Layanan Mandiri Pada SPBU Adicipto Yogyakarta. Journal Pendidikan Matematika dan Sains, Vol 7, No 3.

Feriyanto, E. J., Insani, N. \& Subekti, R. (2016). Optimasi Pelayanan Antrian Multi Channel (M/M/c) Pada Stasiun Pengisian Bahan Bakar Umum (SPBU) Sagan Yogyakarta. Journal Pendidikann Matematika \& Sains.

Hasian, D.P., Putra A,K. (2010). Simulasi Pelayanan Pengisian Bahan Bakar Di SPBU Gunung Pangilun. Jurnal Optimasi Sistem Industri, Vol. 9 No.1.

Jaelani, E. (2015). Optimalisasi Sisitem Pelayanan Untuk Mengurangi Antrian Dengan pendekatan Pendekatan Simulasi Menggunakan Software PRO MODEL (Studi Kasus Pada SPBU Kadipaten, Majalengka). Jurnal Sains Manajemen \& Akuntansi Vol. 7 No. 1

Jaman, J. H. (2014). Penerapan Multiple Channel Model M/M/1 Antrian Pendafttaran Di Rumah Sakit MNX. Journal Teknik Informatika, Vol. 3 No. 1 Tahun 2014

Lusiani, M. \& Irawan, R.A. (2016) Analisis Sistem Antrian Pada Bengkel Mobil Menggunakan Simulasi. Journal of Industrial Engineering \& Management Systems, Vol. 9, No 2.

Mukhlizar. (2016). Simulasi Sistem Antrian pada SPBU 14.236.100 Menggunakan Promodel . Journal Optimalisasi, Vol 2, No 3.

Mayangsari, Y. Prastiwi E,H. (2016). Sistem Antrian Teller Bank Mandiri Sebagai Upaya Meningkatkan Efisiensi Kecepatan Transaksi. Journal Ekonomi \& Bisnis, Volume 1, Nomor 1.

Permatasari, S.R., Helmi. \& Perdana, H. (2017). Sistem Antrian Pengisian Bahan Bakar Sepeda Motor Pada SPBU PT. Fikri Darmawan Kabupaten Lawi. Jurnal Bimaster, Vol 6 No 2. 